\title{
VERSITA
}

DOI: $10.2478 /$ aucft-2013-0018

\section{THE STUDY OF THE BAKING OVENS BY COMPUTER SIMULATION}

\author{
— short communcation - \\ Igor LITOVCHENKO 1
}

\section{National University of Food Technologies, Kiev, Ukraine}

\begin{abstract}
Configuring ovens for baking bread is a complex scientific and industrial problems. Find the best modes of operation allows computer simulation of aerodynamic and thermal processes in the heating ducts and the baking chamber. Shows an example of a motion study of heating gases in areas of attention, shows the typical problems and methods their solutions.
\end{abstract}

Keywords: bake, bread, gas movement, computer simulation, optimization.

\section{INTRODUCTION}

Tunnel ovens for bread are the bakery main units which determine the quality of the finished product. These furnaces are complex technological object. They have several independent heating zones, where are heat flow dividing into upper and lower heating channels. These adjustment mechanisms have a heat supply to the width and length baking chamber.

Important issue for the bakery ovens it a search of the optimum operating conditions. The main criteria set oven: - uniformity of heat flow across the width of the baking chamber; adjusting the heat flux depending on the stage of baking products; low fuel consumption. As a result, the engineering staff at the bakery has a multifactorial problem on a rational methods furnace operation and keeping parameters it within certain limits.

Getting information about the operation of the furnace with temperature, pressure, humidity, which are installed in various locations the baking

${ }^{1}$ Corresponding author. Mailing address: National University of Food Technologies, Kiev, Ukraine. E-Mail: postman3000@yandex.ru 
chamber, does not give full information on what is going on when driving gases. In this case, a computer simulation of aerodynamic processes in the heating ducts and the baking chamber gives a lot of help to workers bakeries (as well as scientists who create new designs bakery ovens).

The author makes a study by computer simulation of various technological equipment of the food industry: in which the movement of fluids and gases to high viscosity. This is a different mixing machines (Luchian et al., 2012), tanks for fermentation and fermentation, dough proofers (Litovchenko et al., 2012), ovens, separators dairy industry, meat cutters and extruders industry, dryers and vacuum machines (Babko et al., 2012), dispensers and pumps (Litovchenko et al., 2011), heat exchangers, coolers and more.

\section{MATERIALS AND METHODS}

To solve this problem the technique was used software package FlowVision (firm "Tesis"), designed to simulate the movement of liquids and gases in machines and devices with simulation the rheological properties of matter, gravity, convection, wall roughness.

The technique of using software package consists of four steps:

- the creation of three-dimensional geometry in the CAD programs,

- assignment of boundary conditions (input, output, wall, etc.),

- assignment of rheological properties product (density, viscosity)

- setting the driving force (velocity, pressure drop, convection, elevation).

Imaging methods of calculation results obtained allow get graphical and numerical data on many factors of the gas and liquid. The information obtained makes it possible to study the work of existing furnaces and prediction of new designs.

\section{RESULTS AND DISCUSSIONS}

Consider the example of the use of computer simulation to study the movement of gases in a typical industrial tunnel furnace hearth area of 50 square meters.

3D model of the gas channels oven is shown in Figure 1. It includes a furnace, three independent heating zones, heating gas recirculation system. The first part of the furnace, which requires a lot of attention - it is a fire-box for combustion of natural gas and produce heating gases. Figure 2 shows the construction of the furnace with heating gas recirculation system and the channels through which gases move are in different zones of the oven. 


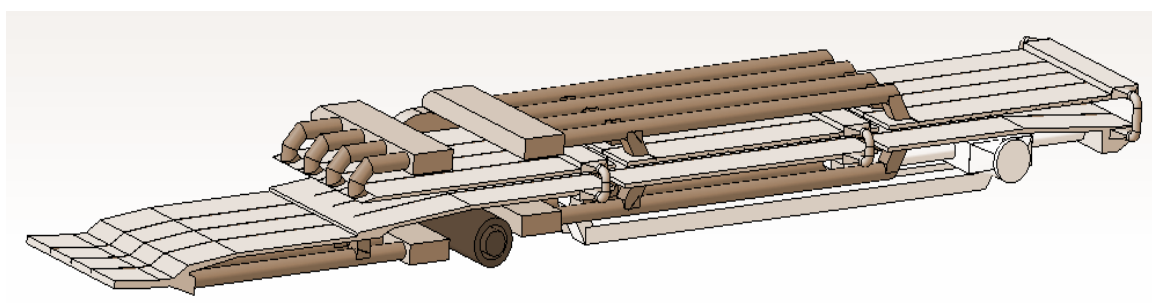

Figure 1. Traffic Pattern heating gases in a tunnel furnace.

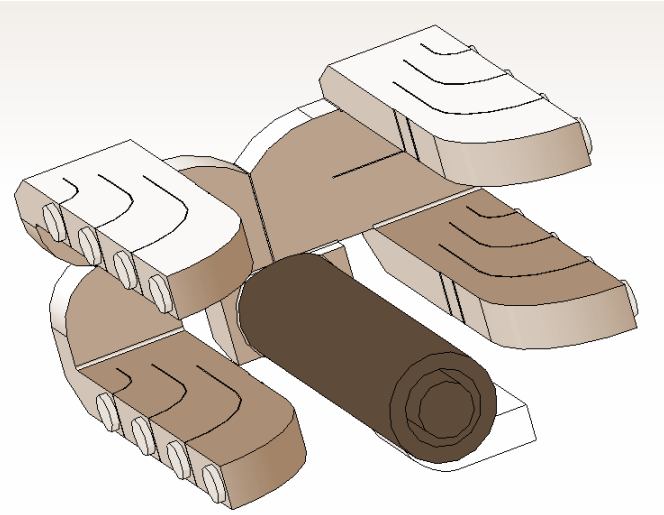

Fig.2. 3D model of the furnace.

The simulation produced the most important data: the speed of gas in vector form (Figure 3), the pressure drops inside the furnace (Figure 4) and the dissipation of energy in the gas streams (Figure 5).

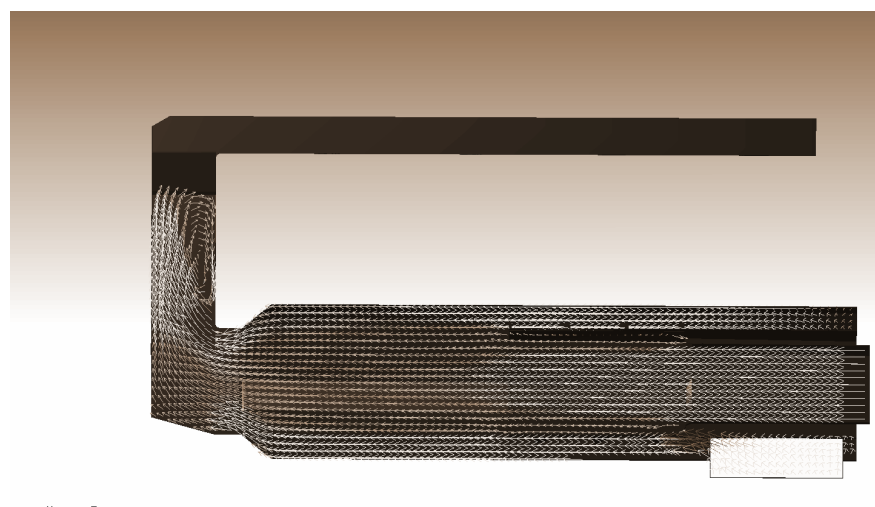

Figure 3. Velocity vectors of the gas in the furnace furnace 
Analysis of Figure 3 allows to notice the area of flow turbulence after leaving the fire-box. At this point there is a loss of pressure and energy flow. Figure 4 shows the pressure difference between fresh combustion gases and recycling. This allows you to install their optimal proportions. Analysis of Figure 5 enables to establish areas in which heat generation due to internal friction in the gas stream. This is corners of structure that lead to energy losses.

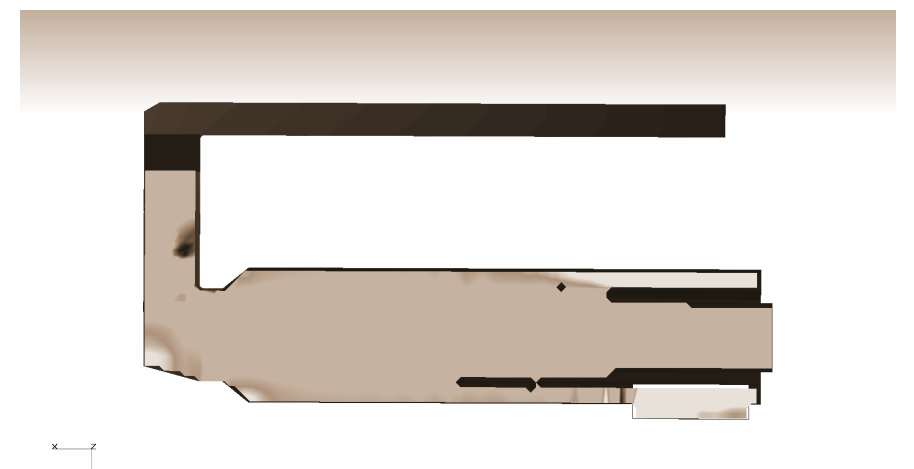

Figure 4. Chănging the gas pressure in the motion along the furnace.

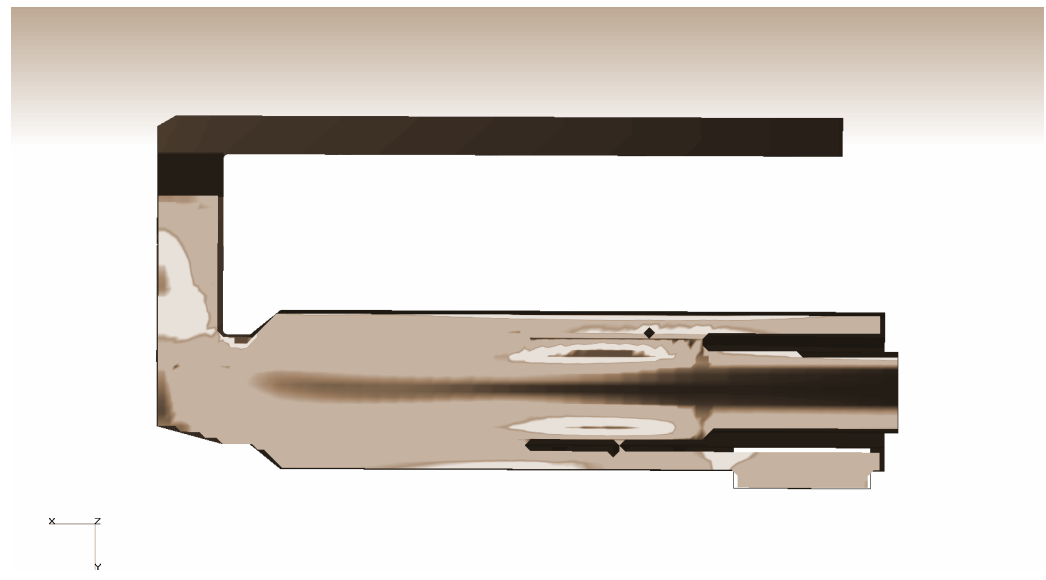

Figure 5. Dissipation of the internal energy of the gas flow in the interaction with the walls of the furnace

In a joint analysis of figures $3 \ldots 5$ can allocate part of the geometry of furnace that require reconstruction. The purpose of reconstruction - reducing pressure losses of the moving gas. It is important to note that changing the geometry of the channels and the velocity of the gas, tested the correctness of

Vol. XVII (2013), no.2 
the solutions proposed computer way. This reduces the amount of time, materials and finance.

In the design of the furnace is an important task - to determine the uniformity of flow distribution across the width of the baking chamber. If no uniformity in various places bread hearth heated in different ways, leading to loss of product quality.

Figure 6 shows a horizontal sectional view of the heating furnace channel. Usually it is divided into several longitudinal channels to reduce lateral movement of gases. The amount of gas in each channel is controlled independently.

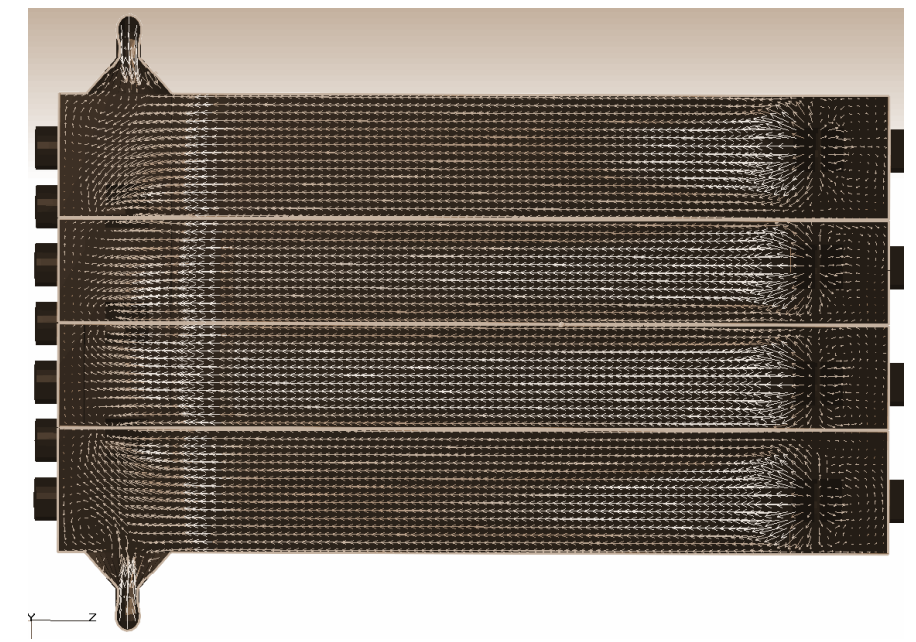

Figure 6. Velocity vectors of the heating gases in the oven (top view)

When analyzing Figure 6 shows that the gas flow rate from left to right consistently changing. This changes the heat transfer coefficient of gas to the channel walls. This in turn leads to variations in temperature the width of the baking chamber, which is a negative factor in the operation.

Way to eliminate these drawbacks is the change in the proportions of channels: the width and height in certain places.

Such studies can be performed for each channel and get a comprehensive picture of gas movement in all parts of the oven.

Next topic of research - the definition of the proportions of gas supply to the upper and lower heat tracing channels. Consider the example of the process gas channels third zone heating furnace (Figure 7). 
It is seen that the basic system construction of venting channels for the fan which is arranged under the lower the heating channel leads to uneven gas pressure. It also affects its speed and efficiency of heat transfer into the baking chamber. An obvious solution is to move the gas extraction ducts in the region between the upper and lower channels.

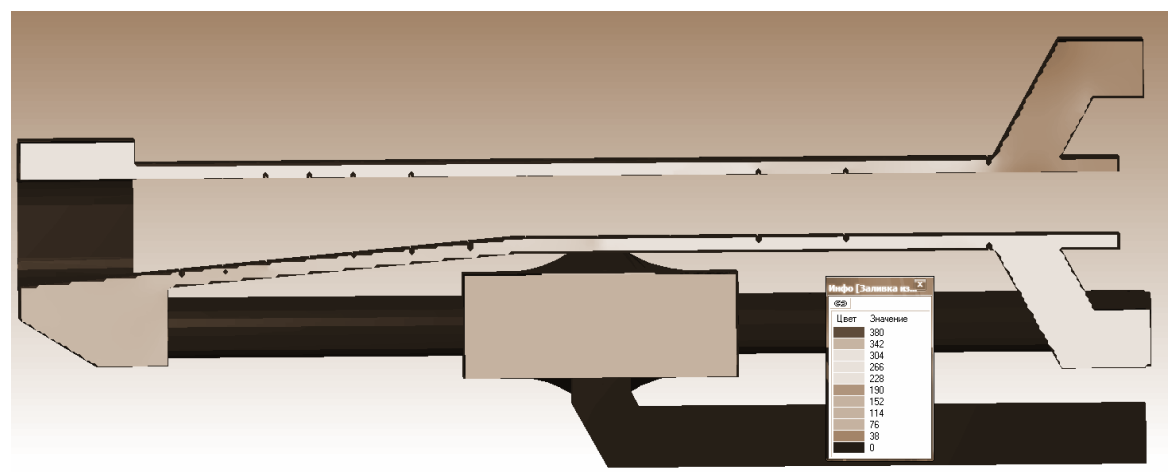

Figure 7. Differential gas pressures in the upper and lower furnace heating water channel

Setting the operation mode. A separate topic of research - is setting temperature conditions in the zones of the furnace. It depends on the position of blades (vanes), installed at key locations kiln gas duct.

Figure 8 shows the effectiveness of dampers that regulate the flow of gases in the heating channels of the common conduit. Gases move from right to left. It may be noted that this current in the furnace control system leads to a pressure drop in the general line.

And it changes the aerodynamic situation in the following them areas of heating. The solution - change the location of the dampers.

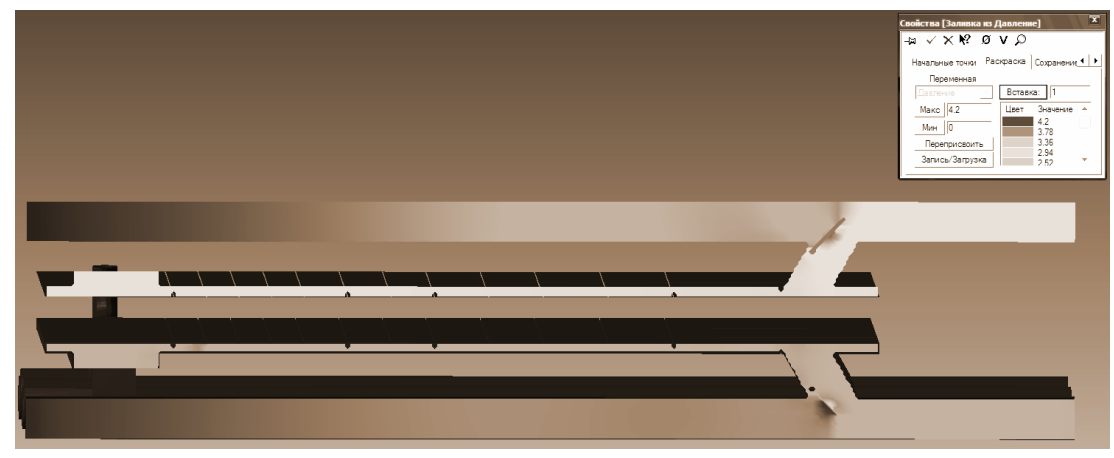

Figure 8. Impact damper on the pressure in the gas channels of the furnace.

Vol. XVII (2013), no.2 
Figure 9 shows a system for regulating the flow of gases leaving the furnace. In this case, the process is influenced by just three flaps. They divide the flow into four channels. The problem of optimal gas moving flow in this case is very complicated. In the production of it is solved by means of measuring the temperature in remote locations channels. In the presence of the large thermal inertia the effectiveness of this technique is small. Using computer modeling allows you to quickly make configuration modes oven.

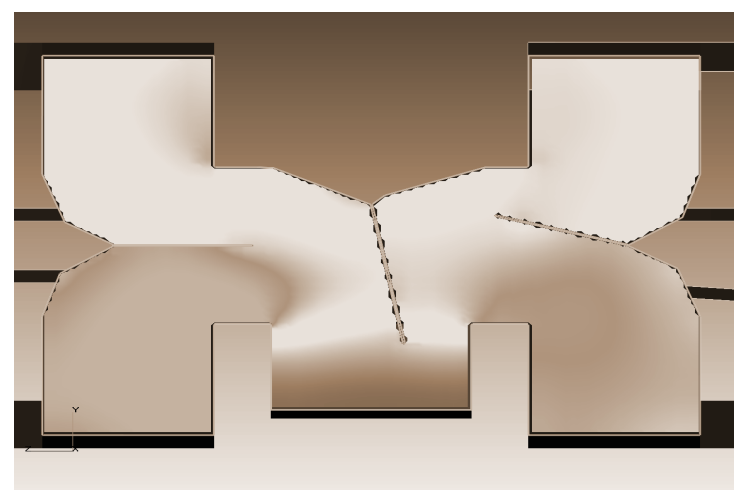

Figure 9. Differential pressures of gases at the outlet of the furnace firebox

When designing developers ovens use different ways of increasing the heat transfer from the heating gases into the baking chamber. One way - setting the devices for the turbulence of the flow. They are relatively small obstacles standing across the stream. The expediency of their use, geometric dimensions and the distance between them can be determined by modeling the flow of gases in places of local resistance.

Analysis of the figure 10 allows to evaluate the activity swirling flow. This decrease is determined by the total flow rate.

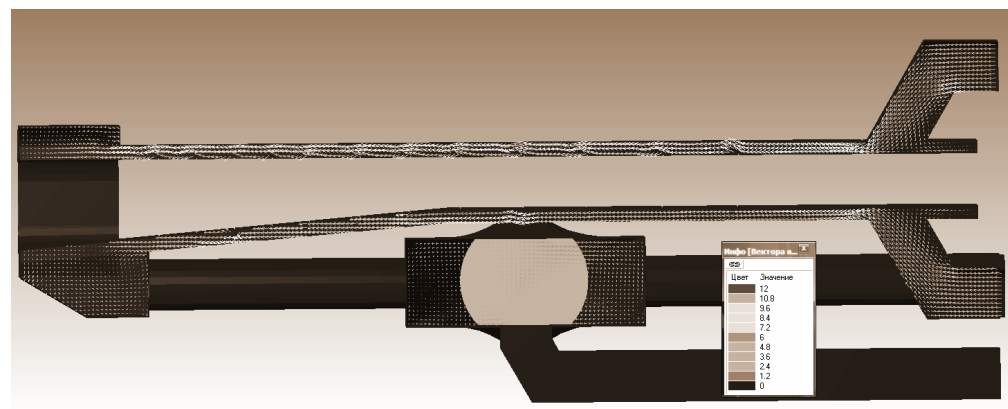

Figure 10 . Velocity vectors of the gas at a flow turbulence

Vol. XVII (2013), no.2 


\section{CONCLUSIONS}

The use of computer simulation of processes of hydro-aerodynamics in ovens for baking bread can significantly improve the quality of their design. This method also allows for the upgrading of existing structures and setting optimum conditions of their work.

In each of the simulations shown numerical values obtained by the flow velocity and pressure changes therein. They are the initial data for numerical methods for calculating the power of the fan recycling, the amount of natural gas that is fed into the furnace, heat loss to the environment and the thickness of the insulation.

Offers cooperation in these and other areas. Please contact us at: inlit@voliacable.com and postman3000@yandex.ru

\section{REFERENCES}

1. Babko E., Litovchenko I., Veresotsky J. (2012). Research of hydrodynamics in the vacuum apparatus crystallization Massecuite with a view to intensifying. (pp. 23-26). Journal of Food and Packaging Science, Technique and Technologies, 1, Bulgaria.

2. Litovchenko I. Hadzhiyski V.M., Stefanov S. (2012). Use of Computer Modeling for Modernization of Final Groofers of Preparation of Dough. (pp. 791-796). 12 International Conference Research and Development in Mechanical Industry RaDMI Vol. 1, Vrnjacka Banja , Serbia.

3. Litovchenko I., Beseda S., Hadjiiski W., Taran V., Stefanov S. (2011). Computer Modeling of Movement Raw Material on Pipelines. (pp. 211214) The 7 International Conference Integrated Systems for Agri-Food Production, Nuireghaza, Hungary.

4. Luchian M., Litovchenko I., Stefanov S., Csatlos C. (2012). Numerical Modeling and Simulation of Bread Dough Mixing using concept of Computational Fluid Dynamics (CFD). (pp. 584-590). 5 International Mechanical Engineering Forum, Prague, Czech Republic. 